\title{
Mechanical and physical properties of Cunninghamia lanceolata wood decayed by brown rot
}

\author{
Shengcai Li ${ }^{(1)}$, \\ Yuewen Gao ${ }^{(1)}$, \\ Michele Brunetti ${ }^{(2)}$, \\ Nicola Macchioni ${ }^{(2)}$, \\ Michela Nocetti ${ }^{(2)}$, \\ Sabrina Palanti ${ }^{(2)}$
}

\begin{abstract}
The relationship between the mechanical properties of Cunninghamia lanceolata (Chinese fir) wood and the development of fungal decay was investigated with the aim of implementing a statistical model useful as a non-destructive and a fast method for determining the state of conservation of in-service timber structures. Artificial decay due to brown rot fungi was induced on wood specimens and physical and mechanical test were performed periodically, as well as anatomical observation of wood, FT-IR spectroscopic and XRD diffraction analysis. As a result, Chinese fir was confirmed to have a good durability against fungi, showing a mass loss percentage of $7.21 \%$ on average after 14 weeks of exposure. On the contrary, the mechanical properties reduced dramatically during the decay test: a $19 \%$ decrease was observed for compression strength and $21 \%$ for tensile strength. The mechanism of decay was explored and the corresponding damage constitutive model was proposed.
\end{abstract}

\section{Keywords: Wooden Construction, Brown Rot, Mass Loss Rate, Wood Decay, Wood Strength}

\begin{abstract}
Introduction
In China, wood has been utilized since antiquity as building material for civil and cultural heritage architecture. Especially in the South of the country, Chinese fir (Cunninghamia lanceolata [Lamb.] Hook.) was often the timber species chosen to this aim (Que et al. 2017). Indeed, Chinese fir is a fastgrowing straight tree whose content in ex tractives confers to the wood a good natural durability (Lu et al. 1987, Chen et al. 2017).

At present, in the country the performance of the materials used for historical building construction and the structural and mechanical behaviour of the wooden buildings are determined principally during emergency reparations and strengthening research projects. Instead, it would be highly desirable to assess the performance
\end{abstract}

(1) School of Architectural Science and Civil Engineering, Yangzhou University (China); (2) CNR-IVALSA, v. Madonna del Piano 6, I-50019 Sesto Fiorentino (Italy)

\section{@ Shengcai Li (lisc@yzu.edu.cn)}

Received: Jul 18, 2018 - Accepted: Apr 03, 2019

Citation: Li S, Gao Y, Brunetti M, Macchioni N, Nocetti M, Palanti S (2019). Mechanical and physical properties of Cunninghamia lanceolata wood decayed by brown rot. iForest 12: 317-322. - doi: 10.3832/ifor2922012 [online 2019-06-06]

Communicated by: Rodolfo Picchio of wood based on the knowledge of both the inherent durability and the climatic conditions (climate and microclimate) where the building is placed. This can also help planning the proper interventions of maintenance during the service life (Teodorescu et al. 2016)

The aim of this study is to find the relationships between the mechanical properties of Chinese fir wood and the development of fungal decay, aimed at the implementation of a statistical model useful as a non-destructive and a fast method for determining the state of conservation of inservice timber structures.

In the past, Wilcox (1978) reviewed the effect of the early decay on wood strength and reported that, referred to brown rot decay on softwood, toughness and impact bending decreased of $60-80 \%$ when the fungal decay, measured as mass loss percentage was around 5-10\%. Later, Winandy \& Morrell (1993) found a linear relationship between the weight losses due to brown rot and the bending strength losses in Douglas fir (Pseudotsuga menziesii). A drastic decrease in bending strength and modulus of elasticity (MOE) was observed in Scots pine during the initial phase of decay and this change was exponential: a $50 \%$ decrease in bending strength for $7 \%$ of mass loss in the case of brown rot and 20\% for white rot; MOE values were reduced by about $50 \%$ in the case of white rot for a mass loss of $40 \%$, while for brown rot a $50 \%$ decrease in MOE was found after a mass decrease as low as 20\% (Witomski et al. 2016). Looking at these findings, other authors proposed to use wood MOE as an indicator of rot-fungal attack, and the results showed actually that it is a sensitive and re- liable indicator of rot-fungal attack, regardless of fungus or wood species. The MOE analysis of untreated wood reduced the 12to 16-week exposure time necessary for the standard mass loss measurement to four weeks (Ma et al. 2017).

In the same context, Chen (2011) performed accelerated decay tests on Chinese fir by brown rot Gloeophyllum trabeum, finding that, when the wooden mass loss rate was $1.35 \%, 5.03 \%$ and $10.12 \%$, the tensile strength parallel to grain of the decayed specimens was reduced of $5.52 \%, 13.21 \%$ and $29.86 \%$ respectively. He also found a relationship among decay, wooden chemical components and the corresponding mechanical strength and suggested that brown-rot fungus reduced the wooden strength for cellulose's depolymerization by combining the evidences found through the FT-IR spectroscopy, the electron-scanning microscope, and the X-ray powder diffraction techniques (Chen 2011). Cowling (1961) added that, even when the wooden mass loss rate is low, brown-rot fungus can reduce the wooden degree of polymerization rapidly (from 1800-2000 to 150-200 glucose units). Moreover, Curling et al. (2002) explored the relationship between the degradation of hemicelluloses and the reduction of wooden mechanical strength, i.e., the reduction of arabinose and galactose can be associated to an early mechanical strength decrease (up to $40 \%$ ), whereas the reduction of mannose and xylan can be observed when the mechanical strength loss is over $40 \%$. Contrastigly, Pizzo et al. (2016) demonstrated that the strength reduction is imputable to both the mass loss occurred in the wood and the different chemical composition between fresh and 
decayed material; namely, the residual strength of the wood is strongly associated to the effective content of holocellulose.

Little research has been done on the development of a constitutive model for decayed wood. Tagarielli et al. (2005) implemented a constitutive model of undam aged wood and developed the correspond ing formulations. Wang (2015) divided the constitutive model into two stages, and simplified them to a linear equation. Work ing with aged wood, Yokoyama et al. (2009) found that the ultimate flexural capacity, rupture energy and fracture strain limits were all lower than those of the orig inal wood, whereas the elastic limit strain was higher. Furthermore, Li (2009) established the aged wooden strength formulation and suggested a calculation method for degenerated strength of timber struc tural element by comparing aged and fresh Cathay poplar. Finally, it was recently reported that multivariate analyses of biochemical and physic-chemical data allowed the prediction of wood strength with accuracy, validated by experimental measurement of the compression parallel to the grain (Kleindienst et al. 2017).

In this paper, the relationship between different degrees of wood decay and the corresponding mechanical properties has been explored and a model for fungal decayed Chinese fir was proposed. At the same time, the deterioration mechanism of wood decay was investigated by combin ing the FT-IR, electron-scanning microscope, and XRD analysis.

\section{Material and methods}

\section{Specimen preparation}

Cunninghamia lanceolata (Chinese fir) 30year-old trees were sampled from Jiangxi ( $\left.27^{\circ} 44^{\prime} 32^{\prime \prime} \mathrm{N}, 114^{\circ} 39^{\prime} 13^{\prime \prime} \mathrm{E}\right)$. Totally, 10 logs (average diameter of $24 \mathrm{~cm}$ ) were collected from the forest according to the $\mathrm{Chi}$ nese standard GB/T1927-2009, which provides the methods to sample trees for physical and mechanical characterization of the wood. Briefly, the sampled trees had a normal growth, without visible defects and with round and straight trunks; no samples from neighbouring trees were collected.

The wood specimens were then prepared from the logs according to the pattern provided in the Chinese standard GB/T1929 2009 (NTC-TSA 2009a, 2009b). Two sets of specimens were prepared, one for com- pression tests parallel to the grain and the other for tensile tests parallel to the grain. The laths for preparing the specimens were sawn from well-chosen logs following the sawing pattern described by the Chinese standard (GB/T1929-2009). The section size of finish-cutting specimen for compression tests was $20 \times 20 \mathrm{~mm}$, while the corresponding height of specimen parallel to the grain was $30 \mathrm{~mm}$. The minimum section size of the effective part of each specimen for tensile test was $15 \times 4 \mathrm{~mm}$. Only specimens clear from defects such as pith, cracks, knots and local grain deviation were kept for the study. For each specimen, the ring number, density, location within laths and log were recorded.

\section{Decay induction}

The fungus Gloeophyllum trabeum Murr. was cultivated by the Institute of Microbiology of Chinese Academy of Sciences (Beijing, China), according to the Chinese standard GB/T1394 2.1-92 (NTC-TSA 2009C), which describes the laboratory test method for determining the natural durability of wood.

At first, the culture dishes inoculated with the fungus were put into electro-heating standing-temperature cultivator for one week; the related wood specimens were sterilized in a high-pressure steam sterilization pot in which the normal temperature is $138^{\circ} \mathrm{C}$. The sterilized specimens were then put in contact with the fungus hyphae, maintained in a climatic chamber ( $\left.\mathrm{T}=28 \pm 2{ }^{\circ} \mathrm{C} ; \mathrm{RH}=75-85 \%\right)$ and checked periodically.

A pre-test was performed to assess the time needed for the mycelium to degrade Chinese fir wooden specimens. Lin et al. (2009) observed a reduction of mechanical strength of $50 \%$ already at an early stage of decay (less than $10 \%$ of mass loss). According to the pre-test results and the findings by Lin et al. (2009), the mechanical tests (described below) were performed every 2 weeks, starting from the sound specimens (time 0 , before any contact with the fungus) up to 14 weeks after inoculation.

\section{Measurements and tests on decayed specimens}

The measurements and the tests performed are summarized in Tab. 1. According to the goals of investigation, ring number, density and the location of each specimen within lath and log, wooden speci-

Tab. 1 - Number and type of specimens used for different tests. $(\mathrm{N})$ : Replicates per decayed period; (1): "compression type" specimen; (2): "tensile type" specimen.

\begin{tabular}{clcc}
\hline Group & Test & Specimen type & N \\
\hline 1 & Mass loss & 1 & $3 \times 8$ \\
2 & Compression parallel to the grain, Chemical & 1 & $6 \times 8$ \\
& components and cellulose crystallinity & 2 & $6 \times 8$ \\
\hline 3 & Tensile parallel to the grain & 1 & $1 \times 8$ \\
\hline 4 & Anatomical observations & & 1 \\
\hline
\end{tabular}

mens were arranged into four different groups: group 1 for the calculation of the mass loss, groups 2 and 3 for the chemical and mechanical tests, and group 4 for anatomical observations (Tab. 1).

Before the tests, all the specimens were kept in the constant temperature-humidity chamber $\left(\mathrm{T}=20 \pm 2^{\circ} \mathrm{C} ; \mathrm{RH}=60-70 \%\right)$; all specimens were marked and weighted. Only the specimens aimed to the calculation of the mass loss were formerly dried in the oven $\left(T=100 \pm 5^{\circ} \mathrm{C}\right)$ to determine the anhydrous weight and then put in the constant temperature-humidity chamber again to reach the equilibrium moisture content. Afterwards, specimens were inoculated with the fungus and put at constant conditions $\left(\mathrm{T}=28 \pm 2{ }^{\circ} \mathrm{C} ; \mathrm{RH}=75-85 \%\right)$ for the scheduled period according to the test scheme.

At the end of each planned decay period, 3 specimens "compressive type" were took out from the chamber, cleaned from superficial mycelium, dried in the oven ( $T=$ $100 \pm 5{ }^{\circ} \mathrm{C}$ ), and weighted. The mass loss was calculated as (eqn. 1):

$$
\gamma_{m}=\frac{M_{1}-M_{0}}{M_{0}} \cdot 100
$$

where $\gamma_{\mathrm{m}}$ is the mass loss of the specimen; $M_{1}$ is the dried mass of the specimen after inoculation; $M_{0}$ is the dried mass of the specimen before the test.

At the same time, 6 specimens for each decay period from group 2 and 3 were at first conditioned at $\mathrm{T}=20 \pm 2{ }^{\circ} \mathrm{C}$ and $\mathrm{RH}=$ $60-70 \%$ until constant mass, then underwent mechanical and chemical analysis.

The specimens "compression type" underwent the compression test and finally the determination of chemical composition and cellulose crystallinity.

The mechanical tests were performed using a universal testing machine (WDW$20 \mathrm{KN}^{\circledR}$, HST, Jinan Hensgrand Instrument Co., Jinan, (hina) with an accuracy of $10 \mathrm{~N}$. The compressive load was applied slowly with a loading rate between 200 and 300 $\mathrm{kPa}$ per second, in order to reach the failure within 1.5-2.0 minutes. Compression strength parallel to grain was calculated as the load at failure divided by the cross specimen area measured at the testing time. Compression modulus of elasticity (MOE) was determined in the straight line portion of the load-deformation curve.

The modifications of the chemical composition after the compression test were analysed by FT-IR spectrograms (infrared spectroscopic analysis), using the infrared spectrometer $\operatorname{Varian}^{\otimes}$ 670-IR+610-IR (Agilent, Santa Clara, CA, USA). For each decay period, 3 specimens "compression type" were chosen randomly and put into the oven up to their dry condition, then ground to powder and briquetted to the transparent ingot by potassium bromide pellet technique, so that the FT-IR spectrograms could be obtained.

The cellulose crystallinity was measured by D8 Advance X-ray Powder Diffractome- 
ter (Bruker, Billerica, MS, USA). The powder was scanned by the XRD in the scan range $5^{\circ}-45^{\circ}$ and at the $0.1^{\circ} \mathrm{sec}^{-1}$ scan speed in triplicates.

As for the specimens of group 3, six specimens per decay period were tested in tension parallel to the grain using the same machine described above for the compres sion tests. The two ends of the specimens were clamped in the grips of the testing machine so that the wider side was in contact with the grips and at a distance of at least $20-25 \mathrm{~mm}$ from the gauge portion. The specimens were mounted vertically. The load was applied slowly with a loading rate between 200 and $300 \mathrm{kPa}$ per second. Tensile strength parallel to grain was calculated as the load at failure divided by the cross area of the gauge portion measured at the testing time; tensile modulus of elasticity was determined in the straight-line portion of the load-deformation curve.

Finally, one specimen "compression type" per each decay period was kept for the anatomical analysis, performed by an environmental scanning electron microscope (XL-30 ESEM, FEI/Philips, Hillsboro, OR, USA). A transverse section (1 $\mathrm{mm}$ thick) was cut from the decayed surface of the specimens, polished and observed by the ESEM.

Data analysis and definition of Decay Constitutive Model (DCM)

\section{Data analysis}

The results of mechanical tests were used to calculate the loss of mechanical performance as the ratio between the mechanical property of sound specimens (before the inoculation with fungi) and the same property measured at several times along the decay period. The loss of performance was related to the mass loss, hereafter indicated as "decay ratio". The values were fitted with linear and polynomial regression.

\section{Definition of DCM}

The stress-strain curves of each specimen were obtained directly during the mechanical test. Thus, the average stress-strain curve of specimens of each decayed condition for compression and tensile tests were calculated. The DCM consisted of the average stress-strain curves of 8 different decayed condition for "compressive type" and "tensile type".

\section{Results and discussion}

\section{Artificial decay}

After decay induction, the mass loss rate at each decay period was calculated and the results are shown in Tab. 2 . These results confirmed the good natural durability of Chinese fir against rot fungi (Lu et al. 1987, Chen et al. 2017), since after 14 weeks of exposure to fungal attacks, the wood material lost only $7.21 \%$ of its mass, on average.

The percentage of mass loss is hereafter indicated as decay ratio $\left(\gamma_{\mathrm{m}}\right)$. The consequent reduction in mechanical properties
Tab. 2 - Average mass loss of the wood samples at different stages of decay after inolculation.

\begin{tabular}{cc|}
\hline $\begin{array}{c}\text { Decay period } \\
\text { (weeks) }\end{array}$ & $\begin{array}{c}\text { Mass loss rate } \\
(\%)\end{array}$ \\
\hline 0 & 0 \\
\hline 2 & 0.24 \\
\hline 4 & 0.9 \\
\hline 6 & 1.4 \\
\hline 8 & 2 \\
\hline 10 & 3.34 \\
\hline 12 & 5.36 \\
\hline 14 & 7.21 \\
\hline
\end{tabular}

was analysed to establish the relationship between the decay ratio and the loss of performance of the material.

The anatomical analysis showed the evolution of microstructure pattern of Chinese fir wood. Some longitudinal anatomical pictures of samples at 0, 4, 8 and 14 week of fungal exposure are shown in Fig. 1. There were no hyphens visible within the tracheid walls at the beginning, but during the first four weeks of degradation brown-rot fungi spread into the wood and multiplied rapidly, scattering around the pits and spreading to other cells through pits. The bordered pits seemed damaged, in facts most of the torus disappeared. At this stage, apparently only bordered pits showed traces of the attack, while fungus did not degrade the cell wall seriously. Af-
Fig. 1 - Changes in anatomical characteristics of a Chinese fir wood specimens inoculated with the fungus Gloeophyllum trabeum at several stages of decay ( 0 , 4,8 , and 14 weeks after inoculation)
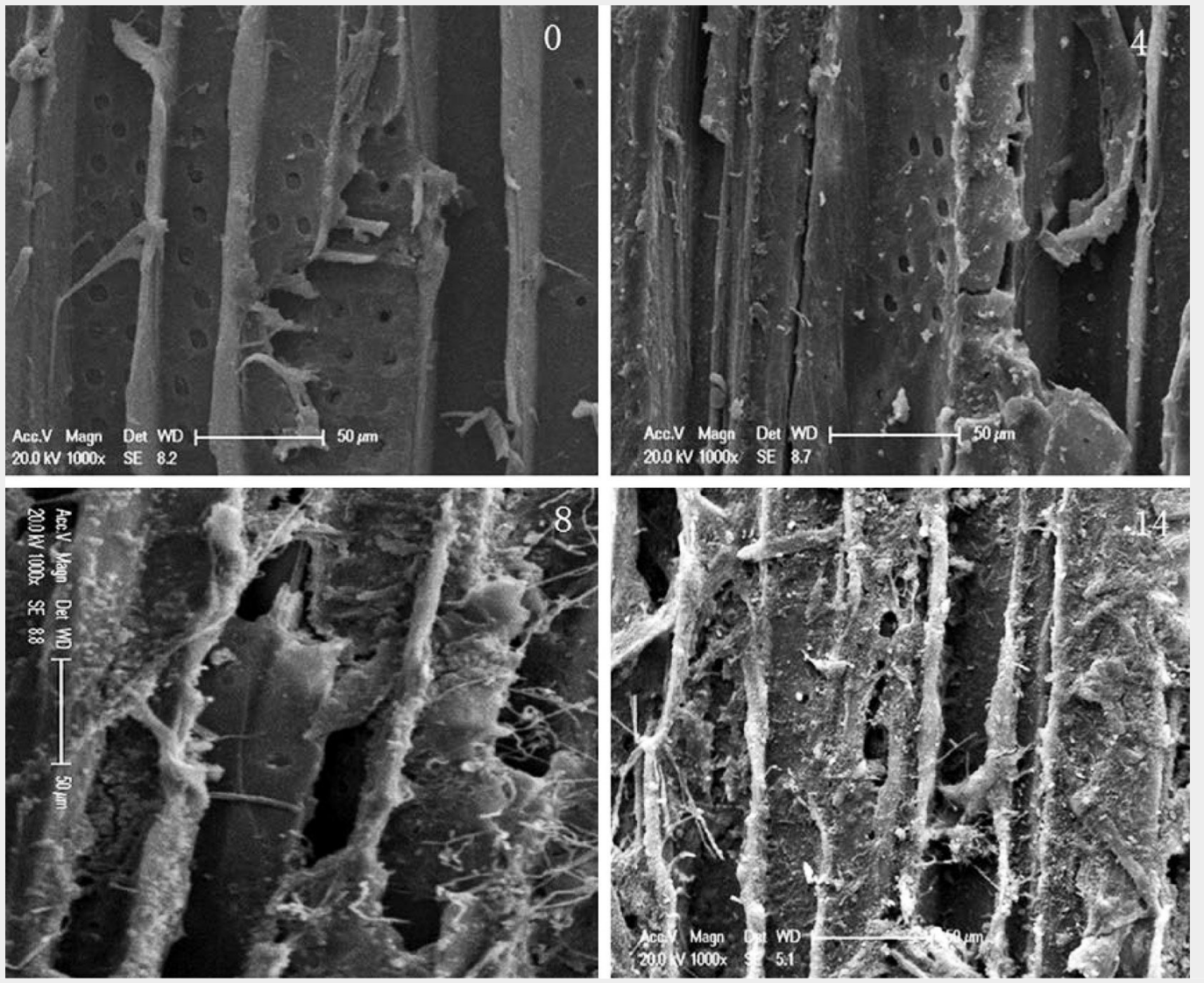
Fig. 2 - FTIR spectrogram of the specimens for 0 (A), 6 (B), 14 (C) weeks of contact with brown rot fungi.

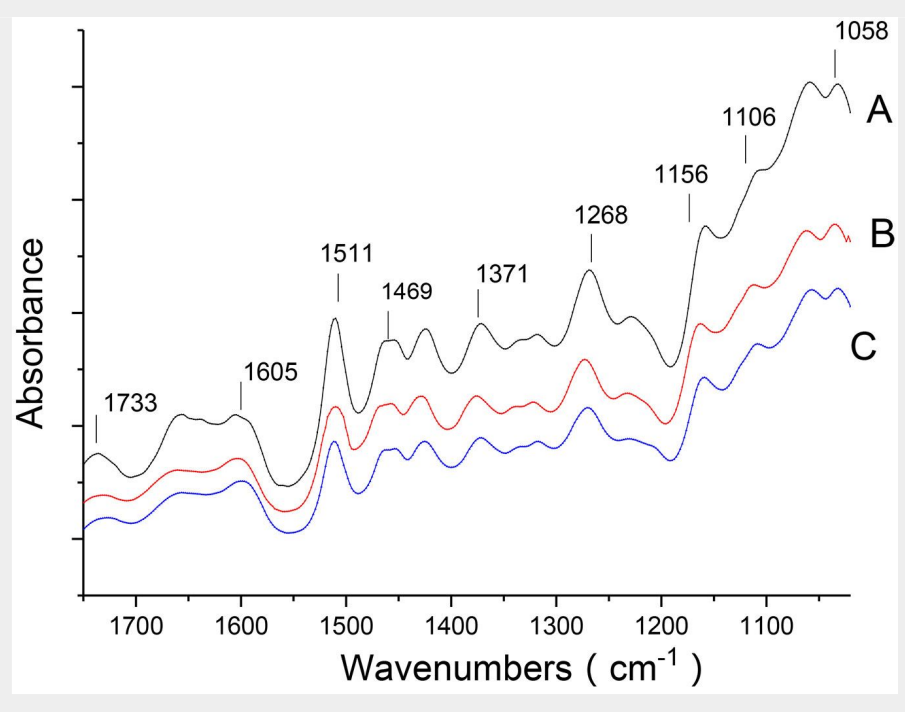

ter 8 weeks, there was mass hyphae within the lumina of the tracheids and the hyphae had invaded and damaged the cell walls. At the same time, the mass and the mechanical properties of those specimen decrease rapidly. After 14 weeks, the tracheid walls appeared decayed and damaged, even if the mass loss was less than $10 \%$. According to the literature (Eaton \& Hale 1993), brown rot fungi mostly depolymerize the holocellulose, causing the reduction in the strength and elastic property of wood, though the mass loss was below 10\% (Pizzo et al. 2016).

There is a wide scientific literature about the use of infrared spectroscopic analysis as a tool for deep investigations on the decay of wood constitutive molecules by fungal rot (Faix et al. 1991), through the evaluation of the molecular interaction between wood polymers and hydrogen bonding within and between cellulose chains ( $\mathrm{Ma}$ réchal \& Chanzy 2000). Using FTIR and XRD analysis, changes in the molecular structure and cell wall composition due to brown rot attack can be studied (Fackler et al. 2010, Durmaz et al. 2016). FTIR spectrograms (Fig. 2) of the specimens at 0, 6, 14 weeks of decay period revealed that the peaks at $1156 \mathrm{~cm}^{-1}$ (C-O-C), $1106 \mathrm{~cm}^{-1}(\mathrm{C}-\mathrm{OH})$, and $1058 \mathrm{~cm}^{-1}(\mathrm{C}-\mathrm{O})$, which are corresponding to holocellulose bonds, decreased with increasing the degradation by fungi. In particular, the intensity dropped more rapidly after 6 weeks. This is due to the fact that in the initial decay period, the fungus feeds on the nutriment of culture medium and wooden cell; but after 6 weeks, when the agar nutrients are exhausted, the fungus degrades more intensely the cell wall, leading to the reduction of the mass and mechanical properties. Moreover, the peak at $1511 \mathrm{~cm}^{-1}(\mathrm{C}=\mathrm{C})$, corresponding to lignin, did not change so much during the experiment. Therefore, the chemical analysis confirmed that the cellulose and hemicellulose were degraded by the fungus, whereas the lignin was less degraded, as expected by a brown rot agent (Eaton \& Hale 1993). On the opposite, the intensity of $1371 \mathrm{~cm}^{-1}(\mathrm{C}-\mathrm{H}$, associated to polysaccharide), $1469 \mathrm{~cm}^{-1}$ (C$\mathrm{H}$, associated to lignin) peaks did not change so much during the test, which is in agreement with the findings by Witomski et al. (2016). Compared to the decayed wood in the waterlogged conditions (Lin et al. 2009, Pizzo et al. 2015), the intensity of $1370 \mathrm{~cm}^{-1}(\mathrm{C}-\mathrm{H}), 1158 \mathrm{~cm}^{-1}$ (C-O-C), and 1104 $\mathrm{cm}^{-1}(\mathrm{O}-\mathrm{H})$ was decreased, while the 1733 $\mathrm{cm}^{-1}(\mathrm{C}=\mathrm{O})$ was also decreased, which is contrasting with out results. This may be due to the fact that the wood here was less decayed out and in different conditions.

The XRD diffraction analysis of the specimens after 0, 6, 10, 14 weeks of exposure to fungi degradation revealed that the cellulose crystallinity decreased rapidly during the test. The peak dropped more rapidly in later periods, because at that time the fungi all survived depolymerizing cellulose and hemicellulose, as already detected by FTIR analysis.

\section{Mechanical properties}

The relationship between mechanical performances (strength and modulus of elasticity) and relative decay ratio was fit based on the test data (Fig. 3, Fig. 4). As expected, both compressive and tensile properties decreased with increasing the decay rate. The loss of strength properties, both tensile and compressive, can be described as merely constant with the development of degradation by fungi. A linear relationship between mass loss and strength properties was found for Douglas fir in bending (Winandy \& Morrell 1993) and for Scot pine in compression (Witomski et al. 2016), while for the last species, the relationship between bending strength and mass loss was better described by an exponential function (Witomski et al. 2016).

After 14 weeks there was $7.21 \%$ of mass loss. Correspondingly, the compression strength decreased by $19.1 \%$ and the tensile strength by $21 \%$. The results are consistent with previous similar analysis on Chinese fir wood (Chen 2011). On the contrary, elastic properties were better described using

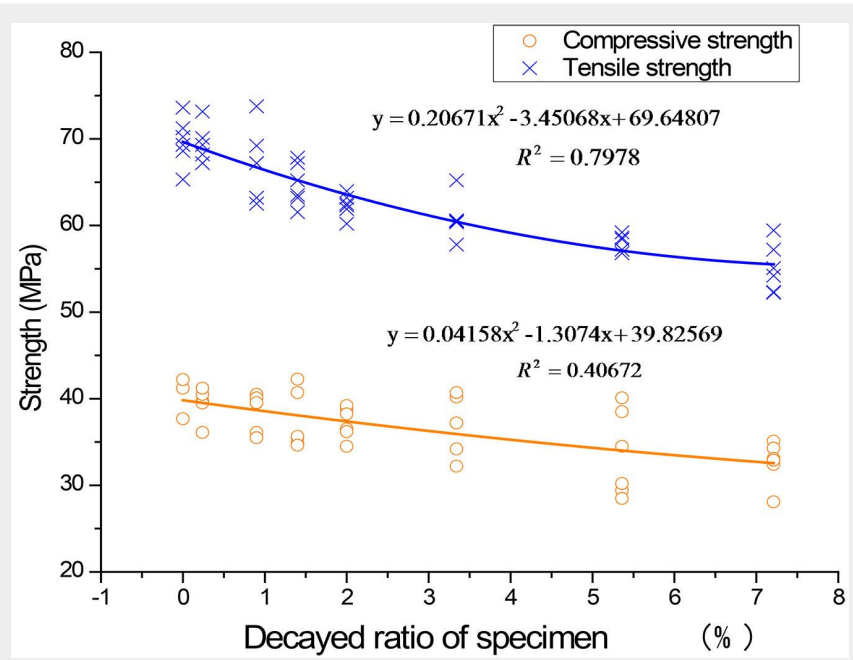

Fig. 3 - Relationship between decay and compressive or tensile strength parallel to the grain.

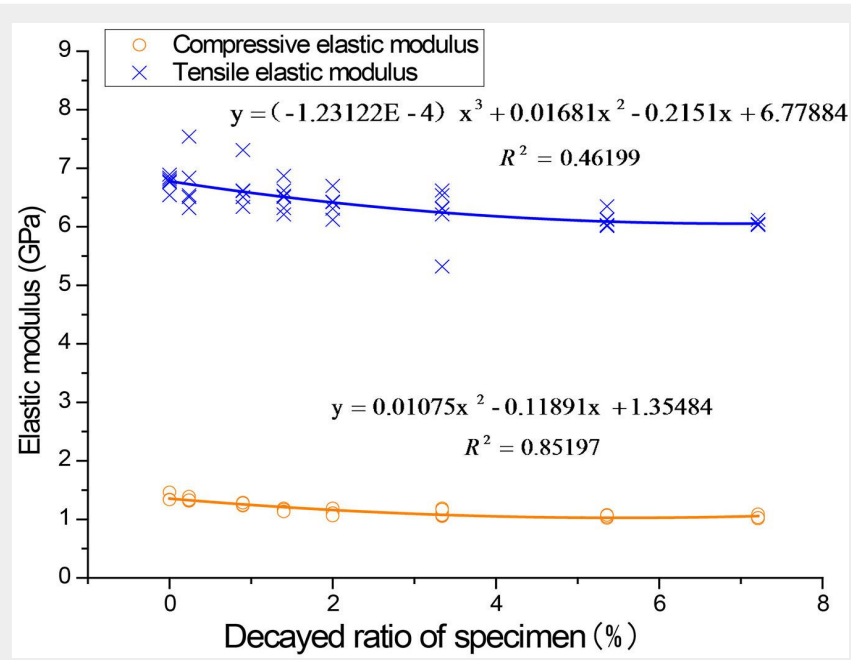

Fig. 4 - Relationship between decay and compressive or tensile modulus of elasticity. 
polynomial regression (Fig. 3, Fig. 4); both compression and tensile elastic moduli decreased more rapidly until the $10^{\text {th }}$ week of fungus exposure, after which the reduction in stiffness showed a smaller rate. At the end of the experiment, the modulus of elasticity in compression and tension decreased by $24.6 \%$ and $10.6 \%$, respectively.

\section{Decay Constitutive Model (DCM)}

A constitutive model describes the stressstrain $(\sigma-\varepsilon)$ relationship of a material. It is a key attribute, which is applied for structural analysis. The stress-strain curves were obtained during the mechanical tests. Fig. 5 shows the average curve for all the 8 decay periods.

The constitutive model followed the basic relationships of wood material. In order to reflect the influence of the different decay grade on the stress-strain relationship, the decay ratio of the specimens along the entire experiment was included in the model. The decay ratios and the stress-strain curves observed in the mechanical tests were used to establish the mechanical degenerated rule in the so called Decay Constitutive Model. The model obtained is the following (eqn. 2):

$$
\sigma=\left\{\begin{array}{c}
\varepsilon \leq \varepsilon_{1}:-682.68 \gamma_{m} \varepsilon+190.603 \varepsilon-42.361 \\
\varepsilon_{1} \leq \varepsilon \leq \varepsilon_{2}:-\left(1338.7 \gamma_{m}+1589\right) \varepsilon^{2}+ \\
\left(90.193 \gamma_{m}+15437\right) \varepsilon+ \\
1.47 \gamma_{m}+1.52 \\
\varepsilon_{2} \leq \varepsilon \leq 0: 38435 \gamma_{m}^{2} \varepsilon-7025 \gamma_{m} \varepsilon+966.88 \varepsilon \\
0 \leq \varepsilon \leq \varepsilon_{3}:-18808 \gamma_{m} \varepsilon+6611.2 \varepsilon
\end{array}\right.
$$

Here, $\gamma_{\mathrm{m}}$ is the decay obtained from eqn. 1 (mass loss) and the values of $\varepsilon_{1}, \varepsilon_{2}$ and $\varepsilon_{3}$ were calculated as follows (eqn. 3):

$$
\begin{aligned}
& \varepsilon_{1}=-0.19 \gamma_{m}-0.0469 \\
& \varepsilon_{2}=0.013 \gamma_{m}-0.005 \\
& \varepsilon_{3}=0.009 \gamma_{m}+0.01
\end{aligned}
$$

The model can be divided into four phases: when the values of strain and stress are positive, the wood material is in the stage of tension: (1) the relationship of $\sigma-\varepsilon$ follows the elastic constructive relation. When the values of strain and stress are negative, the wood material is in the stage of compression and the relationship of $\sigma-\varepsilon$ present three kind of stages with different features. That is, (2) $\varepsilon_{2} \leq \varepsilon \leq 0$, the relationship of $\sigma-\varepsilon$ follows elastic constructive relation; (3) $\varepsilon_{1} \leq \varepsilon \leq \varepsilon_{2}$, the relationship of $\sigma-\varepsilon$ follows elastic-plastic constructive relation; (4) $\varepsilon \leq \varepsilon_{1}$, the relationship of $\sigma-\varepsilon$ follows plastic constructive relation.

The model was based on the test data with a decay ratio between 0 and $7.21 \%$, thus it should be applied for decay levels lower than $7.21 \%$.

From DCM, the specimen for compressive strength parallel to grain were in the elastic stage under invariable original loads. At this time, the loads and the deformation were kept in a linear stage. After it reached the compressive yield stress, the specimen can turn into the elastic-plastic stage.

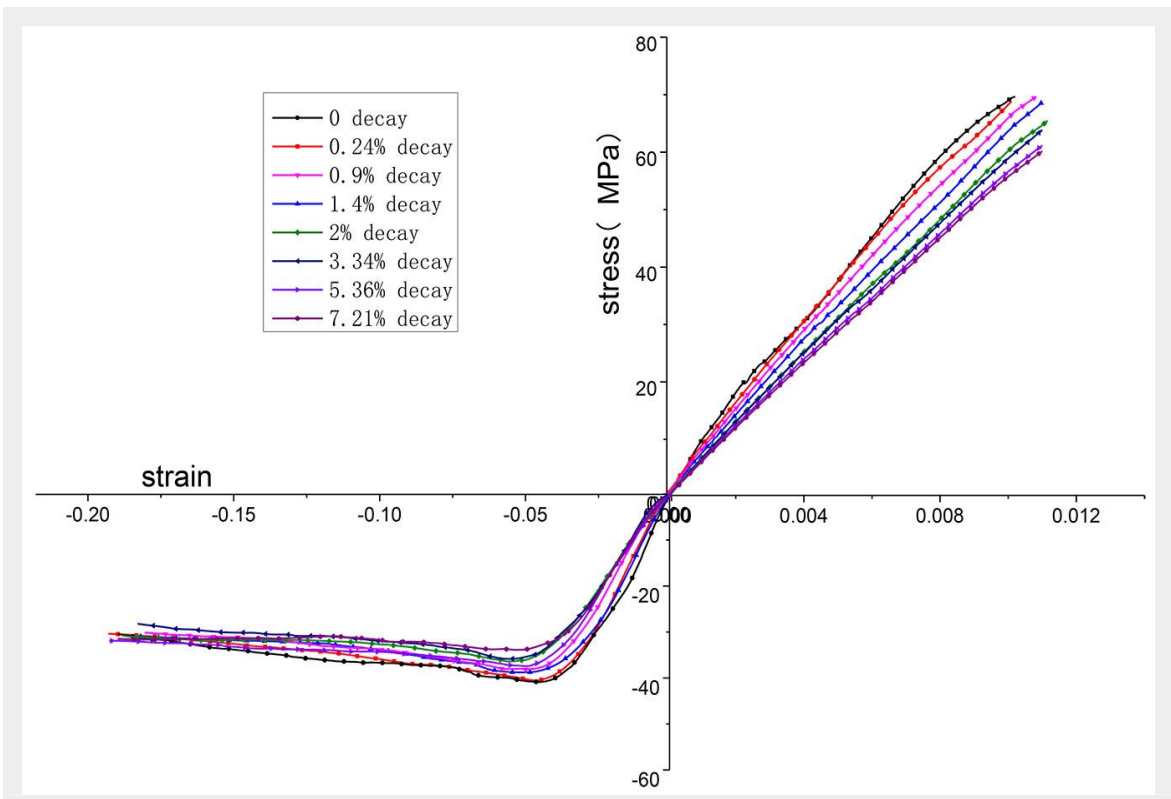

Fig. 5 - Decay constitutive model of wood with incipient brown rot.

Lastly, it was the failure stage when it reached the ultimate compressive strength with the obvious residual strength. Comparing the stress-strain curves of different decay situation, the ultimate compressive strength decreases during the test, so did the elastic modulus, and the decrease became faster after 6 weeks of exposure to brown rot fungus. However, the specimen for tensile strength parallel to grain were in the elastic stage under invariable original loads, and then turn into the failure stage when it reached the ultimate tensile strength with no residual strength. Comparing the stress-strain curves of different decay situation, the ultimate tensile strength and elastic modulus both decrease during the test, and the decrease became faster after 4 weeks of exposure to the fungus.

\section{Conclusion}

The decay test revealed that the mean mass loss percentage after 14 weeks was $7.21 \%$, indicating that Chinese fir wood has a good intrinsic resistance against brown rot G. trabeum. The mechanical properties decreased more dramatically than the physical ones during the decay test: after fourteen weeks of decay, the compressive strength decreased by $19 \%$ and the tensile strength by $21 \%$. The relationship between strength and mass loss can be described by a linear function, while the relationship between the modulus of elasticity and decay percentage is better described by a polynomial function.

The cell wall is seriously damaged by fungal rot, which drastically decreases hemicellulose and crystalline cellulose content, thus reducing the mechanical properties of wood.

The constitutive model of the decay specimen could be divided into four stages: compressive elastic stage, compressive elastic-plastic stage, compressive plastic stage, tensile elastic stage.

\section{Acknowledgements}

This paper is supported by the National Natural Science Foundation of China (Grant No. 51478409, 51338001), the State Administration of Foreign Experts Affair (Grant No. GDT20163200026), Program of 100 Foreign Experts in Jiangsu Province (Grant No. JSB2017029)

\section{References}

Chen $X$ (2011). The influence of incipient brown rot on the properties of Chinese fir at macroscopic and tissue level. Chinese Academy of Forestry Sciences, China, pp. 75-79. [in Chinese] [online] URL: http://xuewen.cnki.net/CMFD-1011 247150.nh.html

Chen M, Wang C, Fei B, Ma X, Zhang B, Zhang S, Huang A (2017). Biological degradation of Chinese fir with Trametes versicolor (L.) Lloyd. Materials 10 (7): 834. - doi: 10.3390/ma10070834

Cowling E (1961). Comparative biochemistry of the decay of sweetgum sapwood by white-rot and brown-rot fungi. USDA Technical Bulletin, vol. 1258, pp. 63-74. [online] URL: http:// ageconsearch.umn.edu/bitstream/170882/2/tb1 258.pdf

Curling S, Clausen C, Winandy J (2002). Relationships between mechanical properties, weight loss, and chemical composition of wood during incipient brown-rot decay. Forest Products Journal 52 (7): 34-37. [online] URL: http://www. fpl.fs.fed.us/documnts/pdf2002/curlio2b.pdf Durmaz S, Ozgenç O, Boyaci IH, Yildiz UC, Erisir E (2016). Examination of the chemical changes in spruce wood degraded by brown-rot fungi using FT-IR and FT-Raman spectroscopy. Vibrational Spectroscopy 85: 202-207. - doi: 10.1016/j. vibspec.2016.04.020

Eaton RA, Hale MDC (1993). Wood: decay, pests and protection. Chapman and Hall, London, UK, pp. 546. [online] URL: http://www.cabdi rect.org/cabdirect/abstract/19940606334 
Fackler K, Stevanic JS, Ters T, Hinterstoisser B, Schwanninger M, Salmén L (2010). Localisation and characterisation of incipient brown-rot decay within spruce wood cell walls using FT-IR imaging microscopy. Enzyme and Microbial Technology 47 (6): 257-267. - doi: 10.1016/j.enz mictec.2010.07.009

Faix $O$, Bremer $O$, Schmidt $O$, Stevanovic $T$ (1991). Monitoring of chemical changes in white-rot degraded beech wood by pyrolysisgas chromatography and Fourier transform infrared spectroscopy. Journal of Analytical and Applied Pyrolysis 21: 147-62. - doi: 10.1016/01652370(91)80022-Z

Kleindienst Q, Besserer A, Antoine M, Perrin C, Bocquet J, Bléron L (2017). Predicting the beech wood decay and strength loss in-ground. International Biodeterioration and Biodegradation 123: 96-105. - doi: 10.1016/j.ibiod.2017.06. 006

Li P (2009). Mechanical mechanism of beam-column joints in wooden frame of Tibetan ancient architecture. PhD thesis, Civil Engineering School, Beijing Jiaotong University, China, pp. 25-32. [In Chinese] [online] URL: http://wenku. baidu.com/view/798f3026dd36a32d7375813d.h tml

Lin J, Zhao G, Zhang W (2009). Microstructure and stress relaxation of the decayed wood by fungi. Journal of Beijing Forestry University 31 (s1): 62-66. [In Chinese] [online] URL: http://www.ixueshu.com/

Lu X, Wang D, Zhou M (1987). Influence of the extractives of Chinese fir wood upon their natural resistance to fungus and termite damage. Scientia Silvae Sinicae 23 (4): 456-462. [online] URL: http://www.linyekexue.net/EN/

Ma X, Kirker G, Clausen C, Jiang M, Zhou H (2017). Modulus of elasticity loss as a rapid indicator of rot-fungal attack on untreated and preservative-treated wood in laboratory tests. BioRescourse 12 (1): 1850-1860. - doi: 10.15376/ biores.12.1.1850-1860

Maréchal Y, Chanzy H (2000). The hydrogen bond network in I_cellulose as observed by infrared spectrometry. Journal of Molecular Structure 523: 183-96. - doi: 10.1016/So022-2860 (99)00389-0

NTC-TSA (2009a). Method of sample tree collection for physical and mechanical tests of wood (GB/T1927-2009). National Technical Committee on Timber of Standardization Administrator of China (NTC-TSA), Standards Press of China, Beijing, China, pp. 3-7. [In Chinese]. [online] URL: http://www.bzfxw.com/soft/sort055/linye/9674 131.html

NTC-TSA (2009b). Method of sample logs sawing test specimen selection for physical and mechanical tests of wood (GB/T1929-2009). National Technical Committee on Timber of Standardization Administrator of China (NTC-TSA), Standards Press of China, Beijing, China, pp. 37. [In Chinese] [online] URL: http://www.zzgui fan.com/webarbs/book/16209/

NTC-TSA (2009C). Method for laboratory test of natural decay resistance of woods ( $\mathrm{GB} / \mathrm{T} 1394$ 2:1-92). National Technical Committee on Timber of Standardization Administrator of China (NTC-TSA), Standards Press of China, Beijing, China, pp. 3-6. [In Chinese] [online] URL: http:// www.zzguifan.com/webarbs/book/49806/9166 13.shtml

Pizzo B, Pecoraro E, Alves A, Macchioni N, Rodrigues JC (2015). Quantitative evaluation by attenuated total reflectance infrared (ATR-FTIR) spectroscopy of the chemical composition of decayed wood preserved in waterlogged conditions. Talanta 131: 14-20. - doi: 10.1016/j.talan ta.2014.07.062

Pizzo B, Macchioni N, Capretti C, Pecoraro E, Sozzi L, Fiorentino L (2016). Assessing the wood compressive strength in pile foundations in relation to diagnostic analysis: the example of the church of Santa Maria Maggiore, Venice. Construction and Building Materials 114: 470480. - doi: 10.1016/j.conbuildmat.2016.03.173 Que Z, Li Z, Zhang X, Yuan Z, Pan B (2017). Wood in civil engineering: traditional wooden build- ings in China. InTech Open, London, UK, pp. 204. - doi: 10.5772/63178

Tagarielli V, Deshpande V, Fleck $N$, Chen C (2005). A constitutive model for transversely isotropic foams, and its application to the indentation of balsa wood. International Journal of Mechanical Sciences 47 (4-5): 666-686. - doi: 10.1016/j.jimecsci.2004.11.010

Teodorescu I, Tapusii D, Erbasu R, Bastidas-Arteaga $E$, Aoues $Y$ (2016). Influence of the climatic changes on wood structures behaviour. Energy Procedia 112 (112): 450-459. - doi: 10.1016/j.egy pro.2017.03.1112

Wang J (2015). Analysis of the structural performance of two and six level wooden model. Taiyuan University of Technology, China, pp. 40-41. [in Chinese] [online] URL: http://max. book118.com/html/

Wilcox W (1978). Review of literature on the effects of early stages of decay on wood strength. Wood and Fiber 9 (4): 252-257. [online] URL: http://wfs.swst.org/index.php/wfs/ article/view/248/248

Winandy J, Morrell J (1993). Relationship between incipient decay, strength, and chemical composition of Douglas-Fir heartwood. Wood and Fiber Science 25 (3): 278-288. [online] URL: http://ir.library.oregonstate.edu/xmlui/bitstrea m/1957/14208/2/relationshipbetweenincipientd ecay.pdf

Witomski P, Olek W, Bonarski J (2016). Changes in strength of scots pine wood (Pinus silvestris L.) decayed by brown rot (Coniophora puteana) and white rot (Trametes versicolor). Construction and Building Materials 102: 162-166. - doi: 10.1016/j.conbuildmat.2015.10.109

Yokoyama M, Gril J, Matsuo M, Yano H, Sugiyama J, Clair B, Kubodera S, Mistutani T, Sakamoto M, Ozaki H, Imamura M, Kawai S (2009). Mechanical characteristics of aged Hinoki wood from Japanese historical buildings. Comptes Rendus Physique 10 (7): 601-611. - doi: 10.1016/j.crhy.2009.08.009 